\title{
Effectiveness of a Multiple Intelligences Teaching Approach Drug Education Programme on Pupils' Attitude to Drug Abuse
}

\author{
Evelyn Nwanebe Nwagu \\ (Department of Health and Physical Education, University of Nigeria, Nsukka, Nigeria)
}

\begin{abstract}
The researcher developed a drug education programme based on Multiple Intelligences Teaching Approach (MITA) and evaluated the effectiveness of same on the attitude of pupils (11 - 13 year old) towards drug. The differential effect of the programme on pupils of different sex and school location were explored. The study, a quasi experimental study involved 91 pupils who were grouped into experimental (taught with the MITA) and control (taught with the usual Traditional Lecture Method) groups. The result revealed that the experimental group had a mean attitude score that was significantly higher than that of the control group. While the MITA had no significant differential effect on pupils' attitude due to sex, its positive impact on healthy attitudinal development was more manifest with urban based pupils. It was concluded that the MITA was more effective than the usual Traditional Lecture Method in helping pupils to develop healthy attitude towards drugs.
\end{abstract}

Keywords: Attitude, Drug abuse, Multiple Intelligences Teaching Approach, Traditional Lecture Method

\section{INTRODUCTION}

\section{1. Background to the study}

Attitudes to alcohol, tobacco and other drugs vary based on socio-cultural setting. In many societies, attitude to drugs are formed as a result of prevailing beliefs and practices. The school however is a social force that can be utilized to change or modifying attitudes and behaviours which the society disapproves of [1]. The school is able to do this through the use of effective teaching approach that is able to help learners attain mastery of subjects for easy transfer of what they learnt to real life situation [2]. The Traditional Lecture Method (TLM) of teaching which is still being adopted by many Nigerian teachers [3-6] has been shown to be flawed and not capable of bringing about the desired effect in learners in drug education and other disciplines [2].

In spite of the school drug education, the number of Nigerian youths abusing drug is increasing and the age of initiating drug use is decreasing [7-10]. The many problems associated with drug abuse have made drug abuse prevention a global concern $[11,12]$. The increase in the prevalence of drug use among Nigerians demands that an effective preventive programme of drug education that will help younger persons develop positive attitude to drug should be developed and used for pupils before they initiate drug use.

Drugs are substances that when taken into the bodies are capable of influencing the structure and or function of the body [13]. They are not only the drugs used in treatment but include other substances such as alcohol, tobacco and marijuana which are capable of influencing body function. Alcohol tobacco and marijuana or Indian hemp have been identified as "gate way" drugs because their use pave way for later use of more potent drugs of abuse such as heroin [14]. The use of these gateway drugs among youths in Nigeria is very common $[12,14,15]$ hence the drugs constitute the focus of this study and are in reference wherever the term 'drug' is used in this study.

Alcohol, tobacco (including cigarettes and cigars) and Indian hemp have been shown to be the most commonly used and abused drugs in most societies [14]. Many adolescents in Enugu state of Nigeria believe that most youths use drugs [3]. Such beliefs and attitudes encourage young people to use and abuse drugs [16]. Therefore experts in drug education suggested that strategies should be developed to counter such normative beliefs and erroneous perceptions about drug use and abuse [17, 18].

Drug abuse is a preventable behaviour [19] and the developmental year's present opportunities for resiliency and for receptivity to intervention programmes that can alter the course of addiction. Identifying an effective educational approach that will enhance the acquisition of positive attitude towards drug will go a long way in helping to reduce the incidence of drug abuse among youths.

Attitudes are often referred to, researched and considered in the discipline of health education and health promotion [20]. Attitude is a relatively enduring organization of beliefs, feelings, and behavioral tendencies towards socially significant objects, groups, events or symbols [21]. It is a psychological tendency that is expressed by evaluating a particular entity with some degree of favour or disfavour [22]. Attitude influences how one acts or behaves. It provides meaning for life. A strong relationship exists between adolescents' attitude to drug and alcohol and the rate of use of these substances [23]. Inculcating the necessary drug related knowledge, attitude, values, beliefs, and skills through an effective drug education programme will help the young people resist drug use and abuse. 
In spite of the several efforts to combat the increasing trend of drug abuse in Nigeria, there has not been any overt indication that the efforts have been fruitful $[9,10,24]$. Many governmental, nongovernmental and religious organizations have being making fervent efforts to combat the production, supply, usage and abuse of drugs with minimal positive results. As a result of the public outcry by Nigerians of the damaging effects of drug abuse and illicit drug trafficking, the Federal Government of Nigeria established the NDLEA via Decree 48 of 1989 (Now CAP N30 LFN 2004) [12]. It is worthy to note that despite the forcing, coercing and intimidation of youths and adults to refrain from drug trafficking and drug abuse, the incidence of drug abuse appear to be on the increase in Nigeria [7, 9, 11,]. Hence experts have recommended drug education for alternative. Drug education is an aspect of health education that seek to: increase young people's knowledge and understanding of drugs, drug use and related issues; to explore a range of opinions and attitudes towards drug use and enable young people to arrive at their own, informed views; and to develop a range of skills relating to drug use and enable young people to make their own, informed decisions about drugs [25]. Research studies have shown that children know and think about drugs to an extent that surprise their teachers and parents [26].

This study developed a drug education package using the Multiple Intelligences Teaching Approach (MITA) to help pupils (aged $11-13$ years) develop healthy attitudes to drugs thereby encouraging them not to initiate drug use. Preventive interventions designed and tested to reduce risk and enhance protective factors can help children at every step along their developmental path, from early childhood into young adulthood [19].

This being the case, an educational intervention package targeted at enhancing positive attitude to drugs among primary school children would help them develop drug use resistance tendencies. Current education programmes on drug use and prevention in Nigeria have been suspected not to be comprehensive, allinclusive, and adequate or appropriate [3, 15]. The traditional lecture method (TLM) is the most common educational approach adopted by teachers in Enugu state of Nigeria for drug education at the primary school level [3].

The traditional teaching approach is described as instructionism [2]. This was the paradigm of the early school system in major industrialized countries. The traditional teaching approach which Nigerian inherited from their colonial masters uses mainly lecture and expository teaching methods $[5,6]$. This traditional teaching approach has continued to persist in most Nigerian formal schools $[3,5,6]$. The traditional teaching approach is built around commonsense assumptions that were never tested scientifically. One of its flaws is that it does not consider several of the learners' characteristic. This approach neglects active student involvement [5, 27]. The "teacher - lecture, student - swallow" model of instruction that characterized the traditional teaching approach had been criticized by educationists [28, 29]. The focus of the traditional teaching approach is on teaching and not learning. Issues that are value laden require method of teaching other than the traditional methods [5].

The young people need an effective educational approach that is capable of challenging the numerous sophisticated advertisements on drugs. This will also help the growing child to acquire the right knowledge, attitude, values and skills to resist drug abuse. Advocates of the Multiple Intelligences Teaching Approach (MITA) claimed that the approach is quite functional and effective with regard to teaching and learning in many disciplines. Will this new approach prove more effective than the traditional teaching approach in helping pupils develop healthy attitudes to drug use?

The use of appropriate educational approach such as the Multiple Intelligences Teaching Approach (MITA) to positively modify pupils' attitude to drug can help youths resist the use of drugs so that they can live healthier drug free life. The MITA is a teaching approach based on the theory of multiple intelligences. Howard Gardner propounded the theory of multiple intelligences [30]. He posits that individuals have eight domains of cognitive ability or intelligences, namely: Verbal-Linguistic, Logical-Mathematical, Musical, Spatial, BodilyKinesthetic, Interpersonal and Intrapersonal Intelligences. Later, Gardner [31] added the Naturalistic Intelligence, and Existential Intelligence. Each of these intelligences is specialized for acquiring knowledge and solving problems in different ways [32]. Individuals are smarter in one or two of these intelligences [33].

The MITA encourages teachers to regard intellectual ability more broadly and to provide multiple opportunities for positive educational experiences with authentic learning outcomes. The MITA allows the learners to actively participate in the education process. This approach has been proved to be an effective teaching approach capable of making great contributions to education at all levels because it adopts several techniques, strategies and tools in teaching all subjects at all levels of education [34].

The aim of this study was to develop and evaluate the effect of a Multiple Intelligences Teaching Approach Drug Education Programme (MITA-DEP) on pupils' attitude to drug use. The study also sorts to find the differential effects of MITA-DEP on the drug related attitudes of male and female pupils, and on urban and rural pupils. 


\section{2. Research questions and hypotheses}

\section{2. 1. Research questions}

1. What is the difference between the mean attitude scores of pupils taught drug education using the MITA and those taught using the TLM?

2. What is the difference between the mean attitudes scores of urban and rural based pupils taught drug education using the MITA-DEP?

3. What is the difference in the mean attitude scores of male and female pupils taught drug education with the MITA-DEP?

\section{2. 2. Hypotheses}

The following hypotheses were formulated and tested at .05 level of significance.

$\mathrm{Ho}_{1}$ There is no statistically significant difference between the mean attitude scores of pupils taught drug education with the MITA and those taught with the TLM.

$\mathrm{Ho}_{2}$ There is no statistically significant difference in the mean attitude scores of urban and rural based pupils taught drug education with the MITA-DEP.

$\mathrm{Ho}_{3}$ There is no statistically significant difference in the mean attitude scores of male and female pupils taught drug education with the MITA-DEP.

\section{1. Research design}

II. METHODS

This quasi experimental study adopted the non-equivalent pretest-posttest control group design. Both the 45 and 46 children who were respectively in experimental and control groups responded to the pretest and posttest instrument

\section{2. Setting}

Enugu State is located in the south-eastern part of Nigeria. The choice of the area is based on the fact that drug use (especially alcohol) is cultural in the area. Alcohol beverages like palm wine, rafia wine, and local gin (kaikai) are produced in large quantities locally and sold openly in local markets, shops and bars. The consumption is permitted without conditions in all cultural activities and in the privacy of homes and farms.

Elders endorse alcohol consumption competition among youths and young adults. Most infants are introduced to alcohol consumption from birth.

The situation is unlike in some states in the northern parts of Nigeria where the sale and consumption of alcohol are prohibited. Moreover in Enugu state, the use (sniffing) of snuff, (which is ground tobacco mixed with potash) is permitted while smoking of cigarette (a form of tobacco) is not so well accepted socially.

Literature shows that drug availability and social factors influence drug use [35]. The socio-cultural environment of Enugu state has all the factors that stimulate drug use and drug abuse. Therefore, children in Enugu state need to be strongly equipped with the right attitude that will help them resist the use and or abuse of drugs, some of which are readily available and socially acceptable.

There were 1178 government owned primary schools in the state at the time of the study. All the government owned primary schools have similar characteristics such as: being all co-educational; having on the average the same teacher/pupil ratio; using the same scheme of work; and teachers still using the traditional lecture method of teaching.

\section{3. Participants}

The population for the study comprised all the primary six pupils in government owned primary schools in Enugu state. They were selected because they were at the end of their primary education and were about entering secondary schools. Secondary school students are exposed to more pressures to use and abuse drug. Pupils in primary six therefore need to be prepared adequately to resist the pressure to use and abuse drug. of Education).

There were 36,365 primary six pupils in the state at the time of the study in 2011 (Data from Ministry

The state had six education zones, namely Agbani, Awgu, Enugu, Nsukka, Obollo Afor and Udi education zones. Nsukka education zone was selected for the study through balloting. From Nsukka education zone, two rural and two urban primary schools were selected (out of the 112 and 116 schools that constitute the rural and urban schools respectively) through simple random sampling (balloting). One intact class was selected from each of the primary six classes in the four sample schools through balloting. One urban and one rural class were assigned randomly to each of experimental and control groups. All the pupils in the selected classes were involved in the study. Approval was obtained from the Parents/guardians of the children after the school authorities had granted permission for the schools to be involved in the study. The sample size was 91 pupils. 


\section{4. Materials}

One attitude scale and two drug education instructional packages were developed, validated and used in this study. The data-collection instrument named Alcohol, Tobacco and Marijuana Attitude Scale (ATMAS) was developed by the researcher to measure the pupils' attitude to alcohol, tobacco and marijuana. The 20 item instrument consists of 10 positive and 10 negative statements about alcohol, tobacco and marijuana. The ATMAS has a 4-point Likert-type scale ranging from strongly agree through agree, disagree to strongly disagree. The scale points were weighted from four to one (4-1) for positively keyed items and one to four (1-4) for negatively keyed items.

The ATMAS was face validated by seven experts in the fields of Health Education, Educational Psychology, Educational Measurement and Evaluation, Sociology, and Curriculum Studies. The critical comments of these experts were reflected in the review and modifications of the items. Only 20 out of the original 26 items of the draft instrument were deemed fit by these experts to be retained in the final version of the instrument used for data collection in this study.

The face validated instrument was trial tested on 20 primary six pupils in a school in Nsukka education zone not sampled for the study. The data generated were used for reliability estimate of the instrument. The Cronbach's Alpha procedure was used to determine the internal consistency of the instrument, and the result was a coefficient of .85 which was considered high enough for the study.

A programme of instruction titled: Multiple Intelligences Teaching Approach based Drug Education Programme (MITA-DEP) was developed by the researcher to ascertain the effectiveness of the MITA in aspects of drug education. The programme contained (i) the specific instructional objectives stated in behavioural terms; (ii) topics for 11 lessons that lasted for a period of 30 minutes each; (iii) teachers activities, and (iv) pupils' activities involving application or use of different intelligences as appropriate. Furthermore, another programme of same contents as MITA-DEP but based on traditional lecture teaching method was designed for the control group

Both the MITA-DEP and the Traditional Lecture Method Drug Education Programme (TLM-DEP) were validated by a team of five experts from the fields of Health Education, Pharmacy, Clinical Psychology, Educational Foundations, and Sociology and Anthropology. The experts rated the contents of the programme as very appropriate, appropriate, inappropriate and very inappropriate as the case may be using an evaluation inventory developed by the researchers. The experts also made specific suggestions for improving the quality of the programmes. After the programmes have been reviewed in the light of the comments and suggestion from experts, the two were trial tested to determine their practicability. For this purpose, two intact classed from the schools not selected for the study were chosen. The lesson plans developed by the researchers in line with the MITA-DEP and LTM-DEP were used. The findings were that the teachers' and pupils' activities prescribed were feasible and the set objectives attainable.

\section{5. Experimental procedures}

Six classroom teachers with minimum qualification of bachelor's degree in education were trained as research assistants on the techniques of executing multiple intelligences based classroom instructions. The training programme lasted for a total of 21 hours which spanned over ten days. During this period the researcher trained the assistants on the steps involved in the administration of the lessons especially the ones with the multiple intelligences approach as this was somewhat strange to the assistants. During the training, the research assistants were exposed to the rudiments of the philosophy, principles of MITA and also drilled in the methodology of the approach. The assistants had time to demonstrate the procedures in the two approaches under supervision. Doubts raised during the training were clarified and misconceptions corrected. After the training, only the best two of the research assistants were retained for the study. Each of the research assistants was assigned to one experimental and one control class in both the urban and rural schools.

Prior to the commencement of the programme, the ATMAS was administered as pretest to both the experimental and the control group. The experimental groups were then taught using the MITA-DEP while the control groups were taught using the TLM-DEP. The teaching lasted for six weeks during which each class had two contacts of 30 minutes each per week. At the end of the treatment (lessons) the ATMAS was administered again as posttest to both the experimental and control groups. Both the teaching and the testing were executed by two research assistants under the supervision of the researcher. The supervision ensured that the lesson plans were strictly followed and that the tests were administered in stress free environments.

\section{6. Control of extraneous variable}

Research assistants were used to implement the programme in order to control for experimenters' bias. The same units of instruction were taught to both the experimental and the control group with the same lesson objectives. The only difference was in the use of multiple intelligences strategies for the experimental group.

Only government owned schools were used for the study since these schools were similar in many 
ways. Analysis of covariance (ANCOVA) was used to analyze the data. The pretest scores were used as covariate to the post test score in order to partial out the initial differences in the attitudes of the pupils to drug.

To control for differences in teacher effectiveness, many possible assistants were nominated and trained but the best two, who were equally consistent in adhering to the lesson plans were involved in the study. They both taught the experimental and control groups in both urban and rural settings. They were of the same qualification and teaching experience.

The pupils were not informed that they were part of a study to avoid curiosity that might lead to interaction. The experimental and the control groups were taught during their usual physical and health education periods and in their normal class setting with the research assistants coming in as specialist teachers. The duration of teaching, topics covered, and test administered were the same for both groups.

The pretest instrument was withdrawn from the pupils immediately after the pretest and kept till the day of the posttest. Pupils were not informed that the scale would be re-administered. Again the duration of treatment (six weeks) was enough to minimize testing effect of the pretest.

\section{7. Method of data analysis}

The total number of items in the ATMAS was 20. Responses to the items were scored. The total score for individual participants fall between a maximum of 80 and a minimum of 20 points. Statistical package for social sciences (SPSS) version 16 was employed in data analysis. Mean and standard deviations were computed to answer research questions, and analysis of covariance was used to test the null hypotheses.

\section{RESULTS}

3. 1. Differences in the attitude of pupils taught drug education using the MITA and those taught using the TLM.

3. 1. 1 What is the difference between the mean attitude scores of pupils taught drug education using the MITA and those taught using the TLM? (Research question 1.)

Table 1Means and Standard Deviations of the Scores of the Attitude of Pupils towards Drugs

\begin{tabular}{|c|c|c|c|c|c|c|}
\hline Group & No & & Pretest & & Post test & Gain Score \\
\hline & & $\overline{\bar{x}}$ & SD & $\bar{x}$ & SD & \\
\hline Experimental & 45 & 53.9333 & 8.4380 & 60.7111 & 9.6780 & 6.7778 \\
\hline Control & 46 & 53.9565 & 8.3346 & 56.2609 & 8.5750 & 2.3044 \\
\hline Diff in mean & & 0.0232 & & 4.4502 & & 4.4734 \\
\hline
\end{tabular}

The result in Table 1shows that the means and standard deviations of the attitude scores of the experimental group in the pretest was 53.93 and 8.43 respectively. The control group had a pretest mean score of 53.96 and a standard deviation of 8.33. The difference in the mean attitude scores of the two groups for the pretest was 0.02 . In the posttest, the experimental group had mean attitude score of 60.71 and the standard deviation was 9.68. The control group had a mean attitude score of 56.26 and a standard deviation of 8.58.

Comparing the mean attitude scores of the two groups in pre and the posttest, the experimental group had a gain score of 6.78 while the control group had a gain score of 2.30. The experimental group therefore had a mean attitude score that was 4.47 more than that of the control group. This shows that the MITA-DEP was more effective than the TLM-DEP in helping children to develop healthy attitude towards drugs.

3. 1. 2. There is no statistically significant difference between the mean attitude scores of pupils taught drug education with the MITA-DEP and those taught with the TLM. (Ho $\left.{ }_{1}\right)$

Table 2 Analysis of Covariance (ANCOVA) Table for Test of main Effect of Teaching approaches on Pupils' Attitude Score in ATMAS.

\begin{tabular}{|c|c|c|c|c|c|}
\hline Source & Sum of Square & df & Mean Square & $\mathbf{F}$ & Sig. \\
\hline Corrected Model & 2906.523 & 2 & 1453.262 & 25.711 & .000 \\
\hline Intercept & 1281.172 & 1 & 1281.127 & 22.665 & .000 \\
\hline Group (Experimental and control) & 453.446 & 1 & 453.446 & 8.022 & .006 \\
\hline Pretest & 2456.022 & 1 & 2456.022 & 43.451 & .000 \\
\hline Error & 4974.092 & 88 & 56.524 & & \\
\hline Total & 318896.000 & 91 & & & \\
\hline Corrected total & 7880.615 & 90 & & & \\
\hline
\end{tabular}

Table 2 shows that the $\mathrm{F}$ ratio of 8.022 with respect to teaching approach was found to be significant at alpha level of .006 . Hence it is also significant at $p \leq .05$. The null hypothesis of no significant difference was 
rejected. This shows that there was a significant difference in the mean attitude scores of the pupils taught drug education with the MITA-DEP and those taught with the TLM-DEP.

\section{2. Difference in the mean attitudes scores of urban and rural based pupils taught with the MITA-DEP}

3. 2. 1. What is the difference between the mean attitudes scores of urban and rural based pupils taught drug education using the MITA-DEP? (Research question 2.)

Table 3

Mean Scores of the Drug Attitude of Urban and Rural Pupils Taught Drug Education with the MITA-DEP

\begin{tabular}{|c|c|c|c|c|c|c|}
\hline \multirow[t]{2}{*}{ Location } & \multirow[t]{2}{*}{ No } & \multicolumn{2}{|c|}{ Pretest } & \multicolumn{2}{|c|}{ Post test } & \multirow[t]{2}{*}{ Gain Score } \\
\hline & & $\bar{x}$ & SD & $\bar{x}$ & SD & \\
\hline Urban & 28 & 58.5000 & 6.0888 & 66.9286 & 5.5239 & 8.4286 \\
\hline Rural & 17 & 46.4118 & 6.0525 & 50.4706 & 5.1976 & 4.0588 \\
\hline Diff in mean & & 12.0882 & & 15.8154 & & 4.3698 \\
\hline
\end{tabular}

The results in Table 3show that in the pretest the urban pupils in the experimental group had a mean attitude score of 58.50 with a standard deviation of 6.09 , while the rural pupils in the same experimental group had a mean attitude and standard deviation scores of 46.41 and 6.05 respectively. In the posttest, the urban pupils had a mean drug attitude score of 66.93 with a standard deviation of 5.52. The rural pupils in the experimental group had a mean drug attitude score of 50.47 and a standard deviation of 5.20. The difference in the mean scores of the two groups in the posttest was 15.82 in favour of the urban based pupils. While the urban pupils had a gain score of 8.43 , the rural pupils had a gain score of 4.06 . The difference in their gain scores was 4.37. MITA-DEP therefore was more effective with the urban based pupils.

3. 2. 2. There is no statistically significant difference in the mean attitude scores of urban and rural based pupils taught drug education with the MITA-DEP. $\left(\mathrm{Ho}_{2}\right)$

Table 4

Summary Table of Analysis of Covariance (ANCOVA) of the Attitude Scores of Urban and Rural Pupils Taught with MITA-DEP.

\begin{tabular}{|c|c|c|c|c|c|}
\hline Source & Sum of Square & df & Mean Square & $\mathbf{F}$ & Sig. \\
\hline Corrected Model & 3012.571 & 2 & 1506.286 & 57.063 & .000 \\
\hline Intercept & 1038.131 & 1 & 1038.131 & 39.328 & .000 \\
\hline School Location (Urban and rural) & 874.409 & 1 & 874.409 & 33.125 & .000 \\
\hline Pretest & 147.419 & 1 & 147.419 & 5.585 & .023 \\
\hline Error & 1108.673 & 42 & 26.397 & & \\
\hline Total & 169984.000 & 45 & & & \\
\hline Corrected total & 4121.244 & 44 & & & \\
\hline
\end{tabular}

It is shown in table 4 that school location as main effect has an $\mathrm{F}$ ratio of 33.125 . This was found significant at .000 as well as .05 levels of significance. The null hypothesis was therefore rejected. It was then concluded that there was a significant difference between the mean scores of the drug attitude of the urban and rural based pupils taught drug education with MITA-DEP.

\section{3. Difference in the mean attitudes scores of male and female pupils taught with the MITA-DEP}

3. 3. 1. What is the difference in the mean attitude scores of male and female pupils taught drug education with the MITA-DEP? (Research question 3.)

Table 5

Means and Standard Deviation of the Pre- and Posttest Attitude of Male and Female pupils taught Drug

Education with the MITA-DEP

\begin{tabular}{|c|c|c|c|c|c|c|}
\hline Sex & & Pretest & & Post test & & Gain Score \\
\hline & No & $\bar{x}$ & SD & $\bar{x}$ & SD & \\
\hline $\begin{array}{l}\text { Male } \\
\text { Female } \\
\text { Diff in mean }\end{array}$ & $\begin{array}{l}21 \\
24\end{array}$ & $\begin{array}{l}54.4286 \\
53.5000 \\
\mathbf{0 . 9 2 8 6}\end{array}$ & $\begin{array}{l}6.9611 \\
9.6774\end{array}$ & $\begin{array}{l}60.9524 \\
60.5000 \\
\mathbf{0 . 4 5 2 4}\end{array}$ & $\begin{array}{l}8.4822 \\
10.7945\end{array}$ & $\begin{array}{c}6.5238 \\
7.0000 \\
0.4762\end{array}$ \\
\hline
\end{tabular}

The result in table 5 shows that while the male pupils had a gain score of 6.52 , the female pupils had a gain score of 7.00. The difference in their gain scores was .48. Though the mean attitude score of male pupils in the experimental group appears to be almost equal, the variance of the scores of female pupils exceeds that of 
the males. This suggests that the pupils who had very low measures in the development of favourable attitude towards drugs could be found among the females.

3. 3. 2. There is no statistically significant difference in the mean attitude scores of male and female pupils taught drug education with the MITA-DEP. $\left(\mathrm{Ho}_{3}\right)$

Table 6 Summary Table of Analysis of Covariance (ANCOVA) of the Attitude Scores of male and female pupils taught with MITA-DEP.

\begin{tabular}{lcllll}
\hline Source & Sum of Square & df & Mean Square & F & Sig \\
\hline Corrected Model & 2139.275 & 2 & 1069.638 & 22.667 & .000 \\
Intercept & 271.072 & 1 & 271.072 & 5.744 & .021 \\
Gender (Male and female) & 1.113 & 1 & 1.113 & .024 & .879 \\
Pretest & 2136.983 & 1 & 2136.983 & 45.285 & .000 \\
Error & 1981.969 & 42 & 47.190 & & \\
Total & 169984.000 & 45 & & & \\
Corrected total & 4121.244 & 44 & & & \\
\hline
\end{tabular}

The result in table 6 shows that the calculated $\mathrm{F}$ ratio of .024 for the main effect of gender was significant only at .879 level of significance. Therefore at .05 level of significance, gender effect is not significant. There was not enough evidence for rejection of the null hypothesis at .05 level of significance. This implies that there was no significant difference between the mean attitude scores of male and female children taught drug education with MITA-DEP.

\section{DISCUSSION OF FINDINGS}

Table 1contains the results on the effectiveness of MITA- DEP in helping pupils to develop healthy attitudes to drugs. The result reveals that while pupils taught with the MITA-DEP had a gain score of 6.78 in the post test ATMAS, those taught with the traditional approach (TLM-DEP) had a gain score of 2.30. The pupils taught with MITA-DEP therefore gained more than those taught with the traditional approach. Table 2 shows that the differences in the mean attitude scores of the two groups were significant beyond .05 level of significance (significant up to .006 level of significant). MITA-DEP was considered more effective than the traditional teaching approach in helping pupils develop healthy attitude to drugs.

This finding is not surprising given the fact that several studies have found MITA to be effective in improving learners' performance when such learners were taught with the approach [36]. The finding is consistent with the findings of a similar study conducted to improve students' motivation, which showed that MITA had positive effect on students who lacked motivation [37]. Students taught in the above study with MITA revealed positive attitude toward themselves and their school. The findings of this work also corroborated the finding of a study in the field of social studies which showed that the application of MITA in teaching social studies significantly increased students' interest and enthusiasm for social studies [38].

The findings of this study could be attributed to the fact that while the MITA-DEP has all the ingredients necessary to help the pupil reconsider wrong values and attitudes held about drug and drug use behaviours such as discussions, debates, role play in addition to questioning and answers, the TLM- DEP used mainly exposition with questions and answers. The interactive sessions through discussions and debates which were components of the MITA-DEP gave the pupils the opportunity to examine their values and stereotyped attitudes developed from existing norms. Research studies have shown that normative education can contribute to effectiveness of drug education programmes as young people often overestimate the usage rate among their peers, and there is an association between perceived peer usage and individual's drug usage [17, 39]. The MITA-DEP allowed the teacher to effectively weave-in normative education through role play. This enabled the pupils reflect over their attitudes and change wrong views and attitude to drug and drug use.

Following from the above, therefore, health educators who want to achieve pronounce positive attitude change to drug use in learners should adopt the MITA as an educational approach for that. Helping the learners to develop healthy attitudes to drug is very essential because attitudes provide readiness for behaviour. Since drug use is a behaviour, learners need to develop healthy attitude to drug use to enable them use drug in a healthy manner or abstain from it. This is even more important for children who have not started using drugs. Their healthy attitude to drug will go a long way in helping them stay drug free or use drug reasonably if they have to.

Significant differences existed in the mean attitude scores of urban and rural pupils taught with the MITA-DEP. The result in Table 3 shows that the urban pupils gained 4.37 scores more than the rural pupils in the ATMAS. In Table 4 the result shows that this difference was found significant at .000 level of significant and it is therefore significant at .05 level of significant. The finding was quite unexpected. The researcher 
expected that MITA-DEP would have had about the same effect on the mean attitude scores of both the urban and the rural pupils because the content and procedure for MITA-DEP was the same for the two groups. Earlier research however showed that significant difference existed in the academic achievements of urban and rural students $[40,41]$. The result of this study may be attributed to the fact that the pupils in the rural setting were found not to be as efficient in the use of English language as the urban pupils. The urban pupils appeared more conversant with the use of the English language than the rural pupils. In Nigeria, English language is the language of instruction for middle basic education (in accordance with the recommendation of the National Policy on Education), therefore the rural and urban pupils were taught using English. The rural pupils who were however less conversant with the use of English were at a disadvantage. The differences in the mean attitude scores of the urban and rural pupils probably would not have been much if they operated at the same level with the urban pupils in terms of their English language comprehension.

The communication process is essential in attitude and value formation. A break in communication will hinder understanding and the expected response will be lost. It is therefore necessary to use language which the learner is very conversant with in drug education if positive change in behviour is to be achieved. Learners who are not conversant with the language of instruction loss interest in the teaching and learning process such that even when effective teaching approach such as MITA is adopted, their educational achievement is reduced. Failure of many drug education programmes are directly linked to failure of such programmes to engage learners' interest because such programmes are not developmentally appropriate or they are too abstract to be meaningful to the learners [42]. Since the rural pupils in this study were evidently deficient in English comprehension, the lessons did not make as much meaning to them as the urban pupils and so their interest and consequently their attitude were not influenced as much as that of the urban pupils.

There was no significant difference in the mean attitude scores of male and female pupils. The mean attitude score gained by the female pupils was slightly higher $(0.48)$ than that of the male pupils (table 5$)$. This difference was found not to be significant at .05 level of significance (table 6). The result was quite expected since both the male and the female pupils were taught under the same condition using the MITA-DEP. Previous researches showed that neither the male nor the female learner is superior to the other with regards to their academic achievement [43,44]. Labeling of one gender as superior to the other through socialization process sometimes bring about differences in the achievement of male and female learners, the differences are not necessarily due to any inborn quality in either of the sexes $[45,46]$.

\section{CONCLUSION}

The MITA can therefore be used to encourage the development of healthy attitudes to drug use in both males and females. The use of suitable teaching methods is a way of enhancing the participation of the learners in the field of science and technology irrespective of gender [47]. This study has proved that MITA is a good teaching approach for both males and females in education in general and drug education in particular.

\section{References}

[1] Federal Ministry of Education (FME) National school health policy. Abuja: FME, (2006).

[2] R.K. Sawyer, The Cambridge handbook of learning sciences (London: Cambridge University Press, 2006).

[3] E.N. Nwagu, The Status of Drug Education in Primary Schools in Nsukka L. G. A. of Enugu state. Journal of Kinetics and Health Education Perspectives (JOKHEP G.C. Abiogu, Socio-political factors in Nigerian education reform: a critical examination. Journal of the Nigerian Academy of Education (JONAED) 6 (1), 2010, 17 - 22.

[4] G.C. Abiogu, Socio-political factors in Nigerian education reform: a critical examination. Journal of the Nigerian Academy of Education (JONAED) 6 (1), 2010, $17-22$.

[5] O.O. Nwaubani, The effectiveness of value clarification strategies in the teaching of some aspects of junior secondary school social studies. International Journal of Education Research (INJER), 8, 2008, 122 - 134.

[6] T.C. Ogbuanya, A.D., and Usoro, Logical sequence instructional technique on academic achievement and retention of students in technical drawing. International Journal of Education Research (INJER), 8, 2008, 35 - 44.

[7] M.L. Adelekan, Trend analysis of substance use among undergraduates of University of Ilorin, Nigeria: 1988-1998. African Journal of Drug and Alcohol Studies, 1 (1), 2000, 39-52.

[8] O.O. Desalu, A.B. Olokoba, A. Danburam, F.K. Salawu, B.M. Issa, Epidemiology of tobacco smoking among adults population in North-East Nigeria. The Internet Journal of Epidemoniology, 6 (1), 2008 Retrieved on 20 th December, 2012 from http://www.ispub.com/journal/the-internet-journal-of-epidemiology/volume-6-number-1/epidemiology-of-tobacco-smoking-amongadults-population-in-north-east-nigeria.html

[9] J. Okoza, and O. Aluede, Drug abuse among students of Ambrose Alli University, Ekpoma, Nigeria. European Journal of Social Sciences, 10 (1), 2009, 85-92.

[10] S. Abubakar, Nigeria losing battle against Indian hemp. Weekly trust online. Saturday, 02 July 2011 . Retrieved on January 10, 2013 from http://weeklytrust.com.ng/index.php?option=com_content\&view=article\&id=6451:nigeria-losing-battle-against-indianhemp\&catid=40: cover-stories $\&$ Itemid $=26$

[11] United Nations Office on Drug Abuse and Crime. Nigeria-country profile. UNODC; 2007. http://www.unodc.org/nigeria/en/abuse.html

[12] National Drugs Law Enforcement Agency: About NDLEA. NDLEA; 2009. http://www.ndlea.gov.ng/v1/?q=content/about-ndlea-0

[13] P,M. Insel, and W.I. Roth, Core concepts in health $\left(9^{\text {th }}\right.$ ed). (Boston: McGraw-Hill, 2004).

[14] A.B. Makanjuola, T.O. Daramola, and A.O. Obembe, Psychoactive substance use among medical students in a Nigerian university. World Psychiatric Association, 6 (2), 2007, 112-114. http://www.blackwell-synergy.com/abs/10.111/j.1360-0443.1976.tb00060.x 
[15] O.A. Adebiyi, B. Faseru, A.O. Sangowawa, and E.T. Owoaje, Tobacco use amongst out of school adolescents in a local government area in Nigeria. Substance Abuse Treatment, Prevention, and Policy, 5: (24) 2010, doi:10.1186/1747-597X-5-24 [http://www.substanceabusepolicy.com/content/5/1/24]

[16] N. McBride, A systematic review of school drug education. Health education Research, 18 (6), 2003, 729-742.

[17] W. Bruvold, A meta-analysis of adolescent smoking prevention programs. American Journal of Public Health, 83, 1993,872 - 880.

[18] D. White, and M. Pitts, Educating young people about drugs: a systematic review. Addiction, 93, $1998,1475-1487$.

[19] National Institute on Drug Abuse. Drug abuse prevention. NIDA; 2007. http://www.drugabuse.gov/publications/topics-inbrief/drug-abuse-prevention

[20] R.M. Cross, Exploring attitudes: the case for Q methodology. Health Education Research 20 (2), 2005, $206-213$.

[21] M. Hogg, and G. Vaughan, Social Psychology, (4th ed) (London: Prentice-Hall, 2005).

[22] Eagly and Chaiken, The Psychology of Attitude (Fort Worth, TX: Harcourt Brace Jovanovich, 1993).

[23] D.B. Towberman, and R.M. McDonald, Dimensions of adolescents drug avoidant attitude. Journal of Substance Abuse Treatment, $10(1), 1993,45-52$.

[24] R. Onike, Causes-Effects of Drug Abuse: implications for Social Studies Teaching. 2010. http://rahaman.wrytestuff.com/swa596799-Causes-Effects-Of-Drug-Abuse-Implications-For-Social-Studies-Teaching.htm

[25] J. Cohen, Drug education: politics, propaganda and censorship. The International Journal of Drug Policy, 7 (3). 1996, http://www.drugtext.org/Education-and-Prevention/drug-education.html

[26] T, Williams, N, Whetton, and A. Moon, Health for Life 1, (Walton on Thames: Nelson).

[27] E. Weber, Multiple intelligences teaching approach. 1996. http://www.mitaleadership.com/mitaeducation/edoline.htm-25kl

[28] B.C. Epanchin, B., Townsend, and K. Stoddard, Constructive classroom management. (California: Wadsworth Inc., 1994).

[29] R.1. Ackoff, and D. Greenberg, Turning learning right side up: putting education back on track. (New Jersey: Wharton School Publishing, 2008).

[30] H. Gardner, Frames of mind (New York: Basic Books, 1983).

[31] H. Gardner, Intelligence reframed: Multiple intelligences for the 21st century (New York: Basic Books, 1999).

[32] K.L. Krause, S. Bochner, and S. Duschesne, Educational psychology for learning and teaching, (2nd ed.), (Australia: Thomson, 2006).

[33] P. Okebukola, Beyond the stereotype to new trajectory in science teaching. (Abuja: Taste and Style, 2002).

[34] L. Prieto, and C. Ferrandiz, Multiple intelligences, Howard Gardner and new methods in college teaching; 2003. http://www.njcu.edu/cill/gardnerbook/forward.asp. December 19, 2008.

[35] C. Amonini, and R.J. Donovan, The relationship between youths' moral and legal perceptions of alcohol, tobacco and marijuana and use of these substances. Health Education Research, 21, (2), 2006, 271-286.

[36] R.G. Owens, and T.C. Valesky, Organizational behaviour in education: Adaptive leadership and school reform, (9th ed) (New York: Pearson Education Inc., 2007).

[37] L.M. Janes, C.L. Koutsopanagos, D.S. Mason, and I. Villaranda: Improving students' motivation through the use of engaged learning, cooperative learning and multiple intelligences; 2000. http://orders.edrs.com $/ \mathrm{members/sp.cfm}$

[38] M. George, J. Mitofsky, and M.B. Peter: Improving students' interest in social studies through the use of multiple intelligences. 2001. http://eric.ed.gov/ERICWebPortal/recore/Detail?accno=ED460926-30k

[39] M. Stead, G. Hastings, and C. Tudor-Smith, Preventing adolescent smoking: a review of options. Health Education Journal, 55, 1996, 31-54.

[40] B.C.N. Okenwa, Location as a factor in students achievement in Introductory Technology in Junior Secondary Certificate Examination in Enugu state. Journal of Education for Professional Growth, 4 (1), 2008, 341-347.

[41] J.U. Akabogu, Effect of school location on students' achievement in reading comprehension. International Journal of Educational Research 1 (1). 2006, 109-114.

[42] N. Tobler, Meta analysis of adolescent drug prevention programs: result of the 1993 meta analysis, in W. Bukoski (Ed.), Metaanalysis of drug abuse prevention programs (NIDA, Bethesda, MD, 1997) 5-68.

[43] S. Nwana, Determination of gender effect using video technique on student teachers' acquisition of non verbal communication skills in microteaching. Journal of Theoretical and Empirical Studies in Education, 2, (1), 2010, 64 - 70.

[44] V.O. Ibegbu, Effect of team teaching on male and female secondary school students. Journal of Theoretical and Empirical Studies in Education, 2(1), 2010, $188-191$.

[45] M.K. Dareng, Women in science, technology and mathematics education; implicationfor teacher education. Journal of Science Teachers Association 42(8), 2001, 395-397.

[46] J.C. Adigwe, Gender differences in chemical problems solving among Nigerian students. Research, Science and Technology Education 10 (2), 1992, 187-201.

[47] A.O. Ogunleye, Science education reform and its implications for the professional development of science teachers in Nigeria, in M.A.G. Akale (Ed.) Proceeding of the $43^{\text {rd }}$ Annual Conference of STAN. (Nigeria: Heinemann Educational Books Plc., 2002) 169177 . 